Serban Al. O. ${ }^{1}$, Obada B. ${ }^{1}$, Radu Georgiana ${ }^{1}$, Zekra M. ${ }^{1}$

\title{
Late results after a new therapeutic protocol for soft tissue management in the treatment of tibial pylon fractures
}

${ }^{1}$ Clinic of Orthopedics and Traumatology, Emergency County Hospital Constanța, Romania

\begin{abstract}
The prospective study targets the tibial pylon fractures admitted in our clinic, to which a new treatment protocol was applied, consisting of two surgical steps, assessing in the end the results achieved at the discharge of the patient and later follows up. The study group consist of 196 patients (198 fractures), in the period 2012-2015.

The average evaluation time was of 16 months. The average age of the patients was 46.5 years (19-83 years), this type of fracture especially affecting active people. The etiology was dominated by high falls (109 cases), most of them being work related accidents. The most frequently applied osteosynthesis principle was staged osteosynthesis which consisted of first stage fibula semitubular plate osteosynthesis and external fixator tibia pylon, followed by minimally invasive or limited approach locked plate tibia pylon fixation. (64.14\%) Olerud and Molander clinical score at more than one year after the last surgical intervention highlights good results: excellent results in the amount of $37 \%$ to $15 \%$ in the first lot, good results $52 \%$ to $29 \%$, moderate success $7 \%$ to $39 \%$ and poor $4 \%$ to $17 \%$.

Two stage surgery protocol with external fixation in emergency and minimally invasive internal fixation with locked plate performed after the dissappearance
\end{abstract}

\section{Bogdan Obada}

Clinic of Orthopedics and Traumatology

Emergency County Hospital,

145 Tomis, Constanta, Romania

email :bogdanobada@yahoo.com of the local edema, as the second surgical step, allows anatomically correct articular reconstruction without skin complications, with decrease of arthitic late complications.

Keywords: tibial pylon fractures, two stage surgery, complications

\section{Introduction}

The prospective study targets the tibial pilon fractures admitted in our clinic, to which a new treatment protocol was applied, consisting of two surgical steps, assesing in the end the results achieved at the discharge of the patient and later follow up. This therapeutical algorithm follows a better preservation of soft tissue, allowing subsequent approach of joint fractures for an anatomical reconstruction and a stable osteosynthesis.

\section{Materials and Methods}

This study comprises all the tibial pilon fractures admitted and treated in the Orthopaedics and Traumatology Clinic of Clinical Emergency Hospital 
of Constanta, in 4 years time. The study group was a prospective batch of 196 patients (198 fractures), in the period 2012-2015.

Inclusion criteria - distal tibia intra-articular fractures

Exclusion criteria - non-intra-articular distal tibia fractures

- tibial malleolus fractures

1. The statistical analysis of the batch was performed on the following criteria: sex, age, etiology, fracture site aspect in AO-Muller classification, soft tissue quality in Cauchoix-Gustilo-Anderson classification.

2. Analysis of immediate complications compared to the traumatic energy

3. Evaluation of the emergency and final therapeutical protocol.

4. Analysis of the long-run results: Olerud and Molander clinical score.

\section{Results}

Table I-Demographic profile of the patients

\begin{tabular}{|l|l|l|}
\hline \multicolumn{1}{|c|}{ Criteria } & \multicolumn{2}{|c|}{ Number } \\
\hline Average age (years) & \multicolumn{2}{|c|}{$46.5(19-83)$} \\
\hline Evaluation period (months) & \multicolumn{2}{|c|}{$16(12-24)$} \\
\hline Sex (men/women) & \multicolumn{2}{|c|}{$156 / 40$} \\
\hline $\begin{array}{l}\text { Simple trauma/high energy } \\
\text { trauma }\end{array}$ & \multicolumn{2}{|c|}{$57 / 139$} \\
\hline Type 43 B (AO) & \multicolumn{2}{|c|}{119} \\
\hline Type 43 C (AO) & \multicolumn{2}{|c|}{79} \\
\hline \multirow{3}{*}{ Open fractures } & Type I & 17 \\
\cline { 2 - 3 } & Type II & 14 \\
\cline { 2 - 3 } & Type III & 17 \\
\hline
\end{tabular}

Diagnosis of the fracture and preoperative planning were based on radiological images of the front and profile, plan and $3 \mathrm{D}$ reconstruction CT scans, which helped both in accurate framing of the diagnosis and achievement of an appropriate and personalized treatment plan for each fracture type (1, $2,3)$.

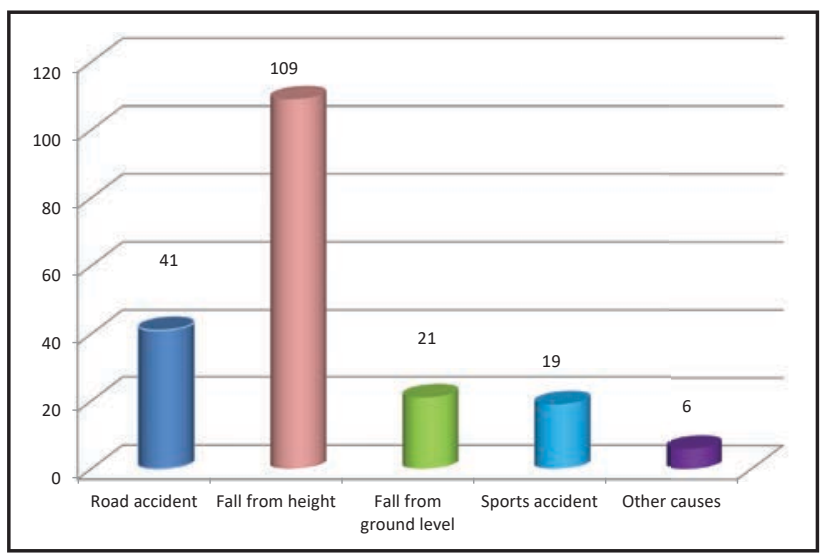

Figure 1 - Etiology

Table II - Emergency fracture fixation

\begin{tabular}{|l|c|c|}
\hline & \multicolumn{2}{|c|}{ AO Classification } \\
\hline & $\mathrm{B}-119$ cases & C -79 cases \\
\hline Cast & 46 & 0 \\
\hline External fixator & 2 & 5 \\
\hline $\begin{array}{l}\text { External fixator } \\
+ \text { fibular plate } \\
\text { osteosynthesis }\end{array}$ & 71 & 73 \\
\hline $\begin{array}{l}\text { External fixator }+ \\
\text { Kirschner wire }\end{array}$ & 0 & 1 \\
\hline
\end{tabular}

Table III - Final fracture fixation - applied osteosynthesis protocol

\begin{tabular}{|l|c|c|}
\hline Method & $\begin{array}{c}\text { Number of } \\
\text { Fractures }\end{array}$ & Percent \\
\hline $\begin{array}{l}\text { One stage } \\
\text { osteosynthesys }\end{array}$ & 46 & 23.24 \\
\hline $\begin{array}{l}\text { Two stage } \\
\text { osteosynthesis }\end{array}$ & 127 & 64.14 \\
\hline $\begin{array}{l}\text { External fixator } \\
\text { as a final method }\end{array}$ & 25 & 12.62 \\
\hline
\end{tabular}


Table IV-Late local complications

\begin{tabular}{|l|c|c|}
\hline Complication & Number & $\%$ \\
\hline Stiffness & 42 & 21.21 \\
\hline Neuroalgodistrophy & 18 & 9.1 \\
\hline Chronic edema & 8 & 4 \\
\hline Consolidation delay & 6 & 3 \\
\hline Vicious callus & 7 & 3.5 \\
\hline Pseudarthosis & 2 & 1 \\
\hline Arthrosis & 25 & 12.6 \\
\hline Osteitis & 0 & 0 \\
\hline Refracture & 2 & 1 \\
\hline Secondary arthrodesis & 0 & 0 \\
\hline
\end{tabular}

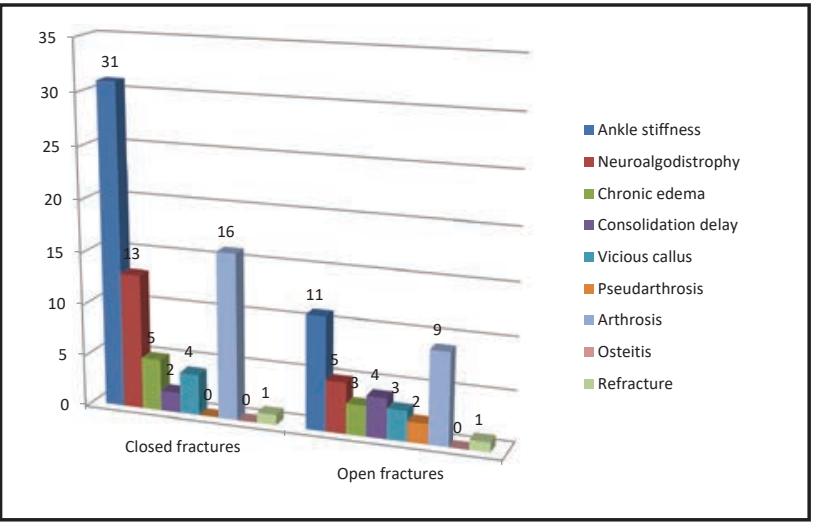

Figure 2 - Late local complications

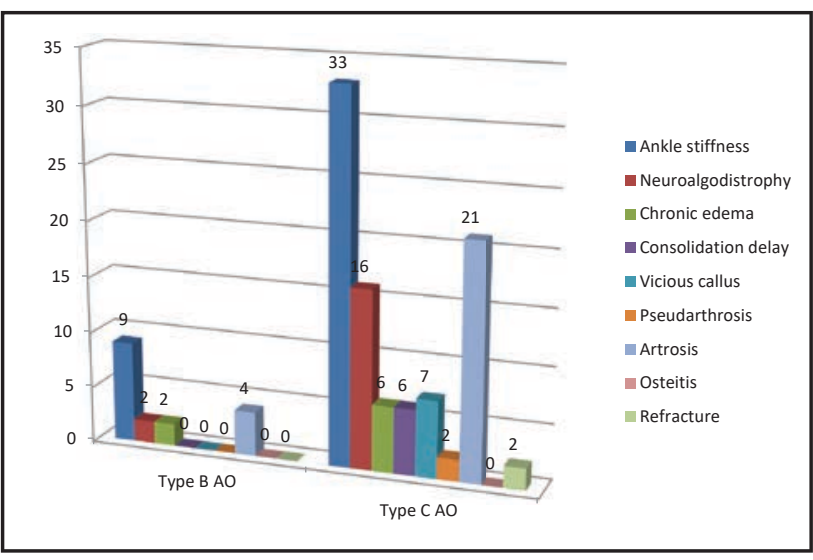

Figure 3 - Late complications (AO)
Assessment of results in time (minimum 1 year - postoperative)

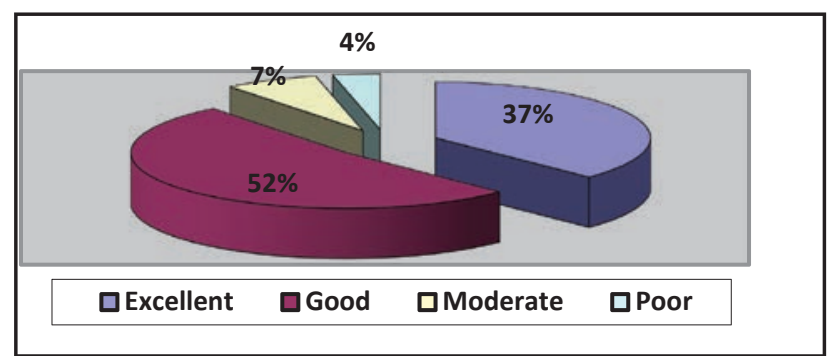

Figure 4 - Olerud and Molander score

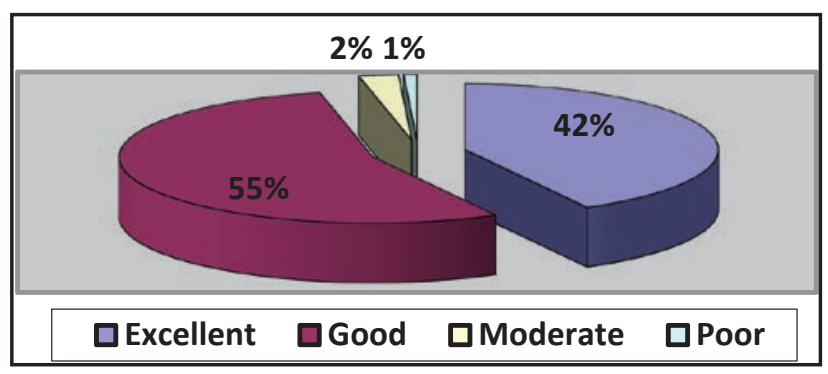

Figure - 5 Type B fractures

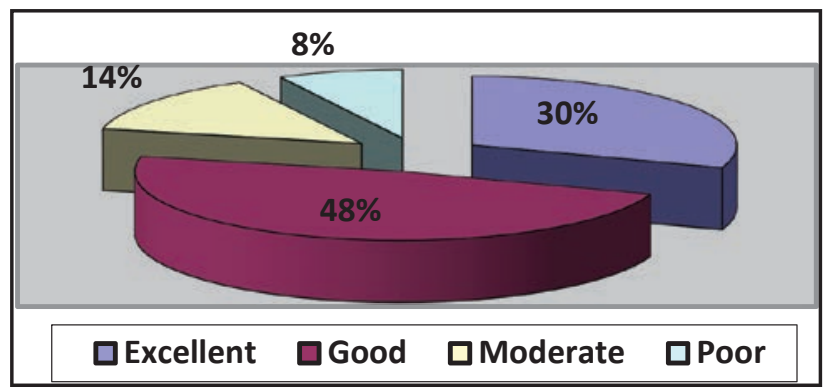

Figure 6 - Type C fractures 


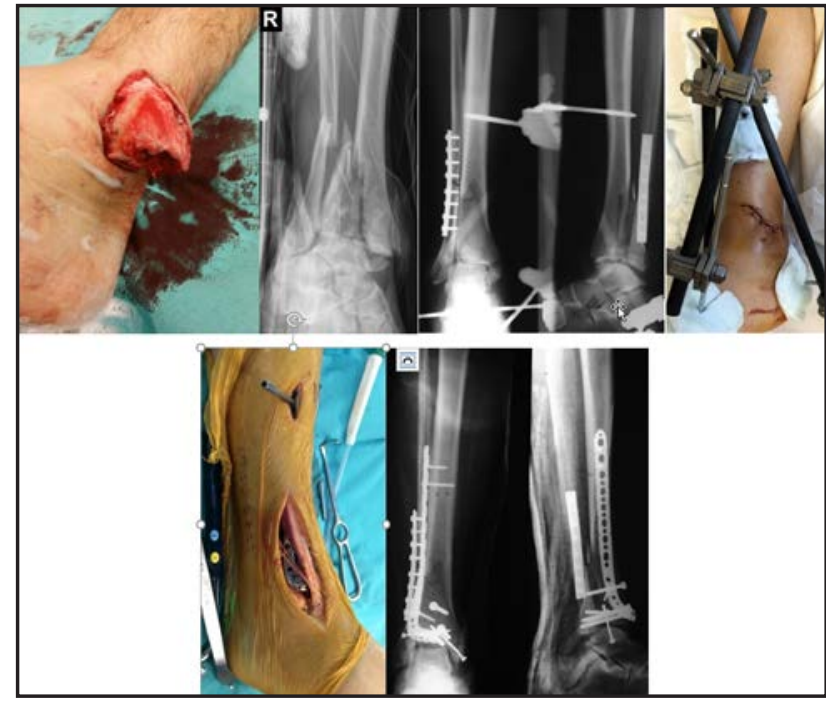

Figure 7 - Case 23 Open right tibial pilon IIIB fracture $43 C 2$ with fibula fracture. Staged osteosynthesis: first step debridment and external osteosynthesis of pilon, fibula plating, followed at 16 days, after the healing of the wound, minimal invasive plate osteosynthesis.

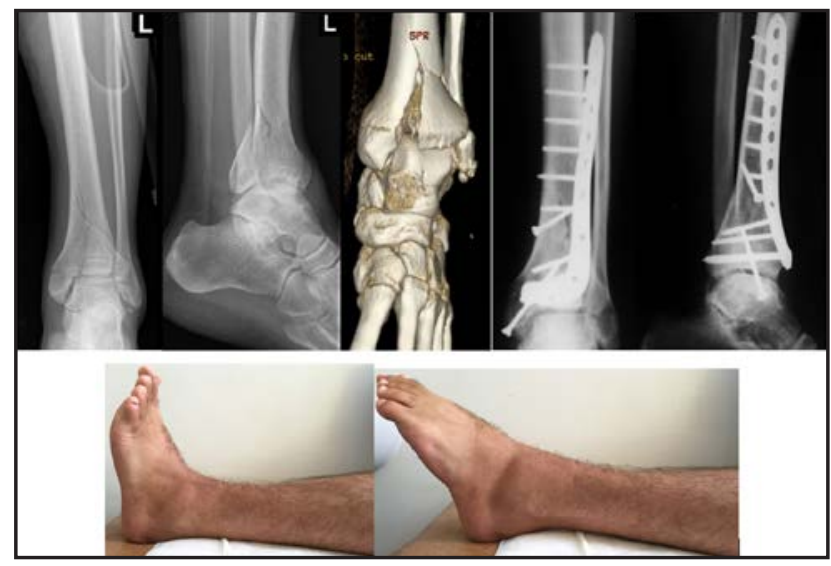

Figure 9-Case 2043 C1 fracture, locked plate osteosynthesis. 6 months postoperative appearance, consolidated fracture, complete functional recuperation. 92 Olerud-Molander score.

\section{Discussion}

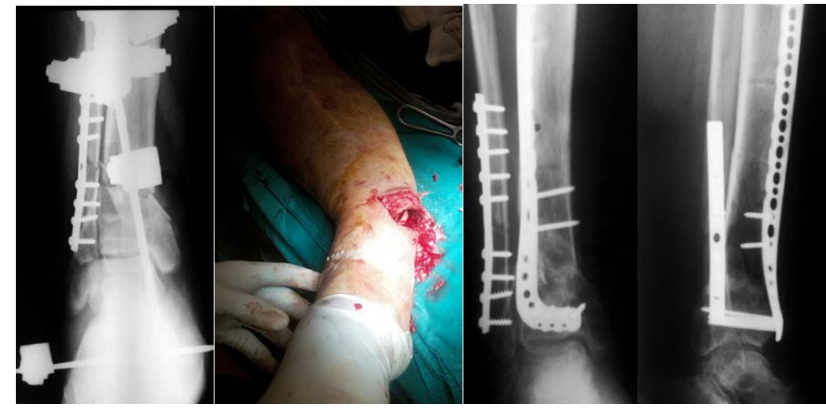

Figure 8-Case 2143 C2 fracture, open type IIIB, staged osteosynthesis. Good functional recovery. 75 Olerud Molander score.
The evaluated prospective group consisted of 196 patients with tibial pilon fractures, of which two had bilateral tibial pilon fractures, resulting in a lot of 198 tibia pilon fractures. The average evaluation time was of 16 months. The average age of the patients was 46.5 years (19-83 years), this type of fracture especially affecting active people. The etiology was dominated by high falls (109 cases), most of them being work related accidents. (table I, figure 1)

The most frequently applied osteosynthesis principle was staged osteosynthesis which consisted of first stage fibula semitubular plate osteosynthesis and external fixator tibia pilon, followed by minimally invasive or limited approach locked plate tibia pilon fixation. (64.14\%) A very important remarcable aspect is the fact that there were no secondary open fractures, and the number of the ischemia skin lesions fractures was small (11 fractures).

After the external fixation of the open fractures and high energy traumatism fractures, the soft tissue evolution was towards healing, which allowed sequencial osteosynthesis with locked plate fracture 
fixation, preferably as a second measure, for 127 tibia pilon fractures, representing $64.14 \%$ of the studied batch.

The targets of the surgical treatment are: soft tissue protection, anatomical reduction of the fracture, stable osteosynthesis and rapid mobilization. [9] We have tried to develop a therapeutic protocol that will reduce late complications, especially arthrotic type. The fundamental element of the therapeutic protocol targets staged osteosynthesis, in two steps, of the tibial pilon fractures, in order to stabilize skin lessions and perform a non-agressive surgical approach of the soft tissue.

The therapeutic protocol follows, as the first step, the osteosynthesis of the fibular fracture, restoring the fibular length, and stabilizing the tibial pilon fracture with a delta external fixator, followed by, in a second surgical time, given by the state of the soft tissue, pilon osteosynthesis with a minimaly invasive incision or a limited approach of the open site of the fracture, with a type "L" locked plate. In the second surgical step, the location of the approach and the type of the implant was given by the location of the skin lesions, which was mostly on the medial side, this leading to the avoidance of this area. [10, $11]$.

Principles of local treatment consist of: closed fractures -orthopaedic measures - type B fractures produc by low kinetic energy, external fixator osteosynthesis - high energy trauma fractures or any fracture at risk for skin lesions; open fractures: debridement, external fixator osteosynthesis.

Emergency external fixator osteosynthesis obtains a primary reduction by ligamentotaxis, which will facilitate internal osteosynthesis as a second surgical step, or allow, if this is not possible, the choice of external fixation as a definitive method of fracture stabilization. (table II)

Tibial pilon fracture osteosynthesis was the final treatment chosen in $100 \%$ of the cases, one step osteosythesis being used in $23.24 \%$ cases, external osteosynthesis as a final treatment in $12.62 \%$ cases, staged osteosynthesis, in two steps, was used in the majority of cases, $64.14 \%$. choosing of the final osteosynthesis moment, is important to avoid skin and infectious complications, especially for primary fixation. (table III) The most dangerous moment is considered to be between 3 and 5 days postoperatively, with the highest rate of local late complications.

The two steps approach of the tibial pilon fractures stabilized the soft tissue in emergency, which allowed further articular reconstruction and stabilization, which made it possible to achieve the two key objectives in the treatment of any articular fracture namely anatomical reconstruction and rapid mobilization. Chosing of the second osteosynthesis moment depends on the local appeareance of the soft tissue, the key points being the decrease of the edema and the normal appearance of the skin. $[12,13]$

The percentage of late complications increases with the comminution rank and joint detritment according to $\mathrm{AO}$ fracture clasification. In case of type $\mathrm{B}$ AO fractures, stiffness in found in $7.5 \%$ of the cases, chronical edema in $1.6 \%$ of cases, neuroalgodistrophy in $1.6 \%$ of cases, while in type $\mathrm{C} \mathrm{AO}$ fractures these rates are much higher, most complications being encountered in this category. Causes are the increasing of the fracture site complexity, limitation of reconstruction possibilities and prolonged articular imobilization time. (figure 2, 3, table IV)

Severity of trauma that caused the fracture is predictive of long-term results of treatment. Late results were better in low energy trauma which had a rotationally producing mechanism of the fracture, comparing to high energy trauma with severe axial loading mechanism, which had important comminution and articular blockage, as found in 43 C3 AO type fractures.

Olerud and Molander clinical score at more than one year after the last surgical intervention highlights good results: excellent results in the amount of $37 \%$ to $15 \%$ in the first lot, good results $52 \%$ to $29 \%$, moderate success $7 \%$ to $39 \%$ and poor $4 \%$ to $17 \%$. (figure 4 )

Regarding evaluation results according to $\mathrm{AO}$ fracture classification, the proportion of favorable outcomes decreases directly proportional with the type of fracture and articular comminution rate. If in case of type B AO fracture we mention osteoarthitis in $6 \%$ of the patients ( $25 \%$ of the retrospective batch), in type C AO fractures we reffer to $30 \%$ of the patients (63\% of the retrospective batch). (figure 5,6 ) 


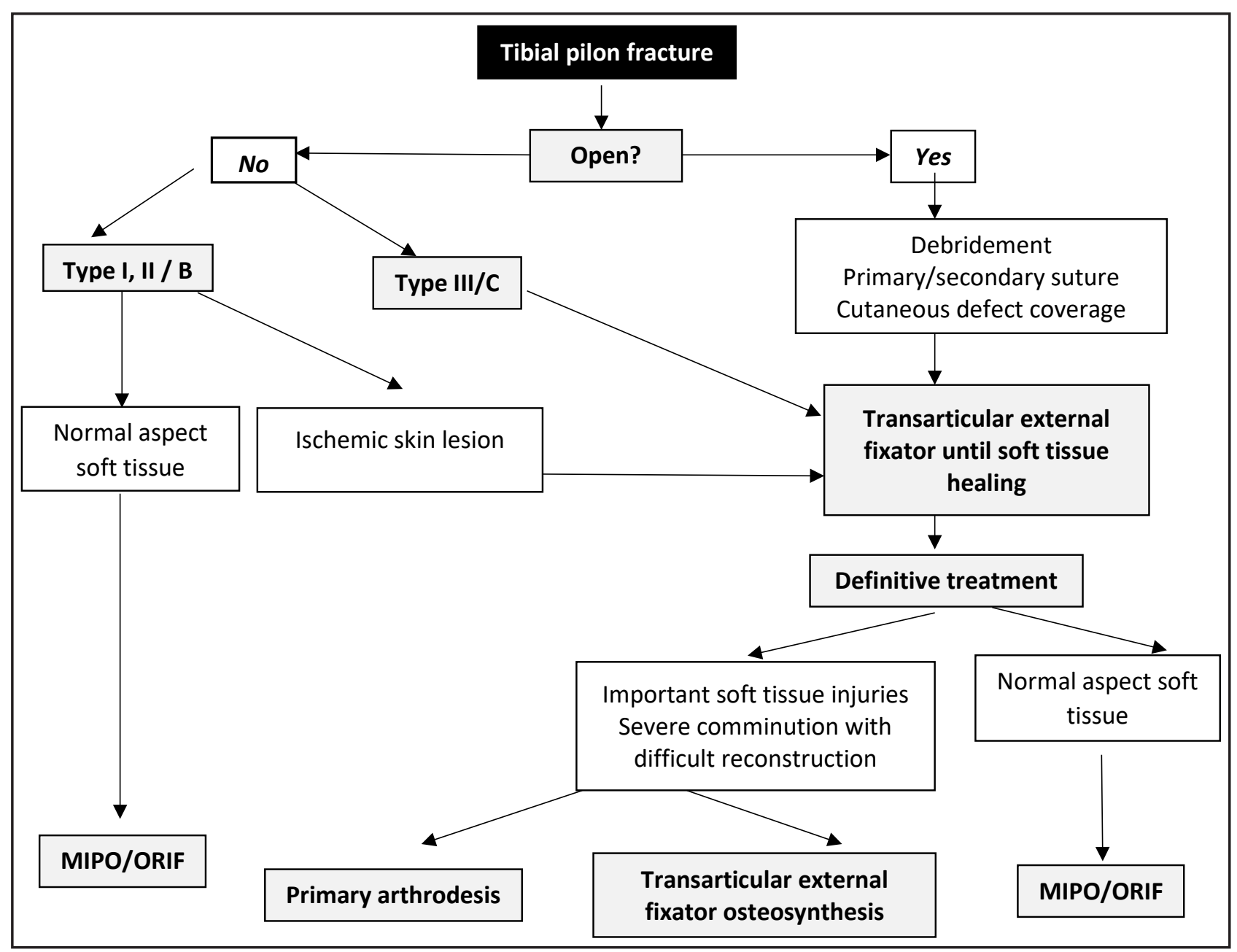

Fig.10 Algoritm of tibial pilon fractures treatment

\section{Conclusions}

External fixator osteosynthesis of the pilon after restoration of fibular lenght and stabilizing the fracture with semitubular plate is the ideal emergency therapeutical option for tibial pilon fractures, achieving a genuine local damage control by simultaneous fixation of fracture and soft tissue.

The applied therapeutic protocol in the prospective lot with the use of two stage osteosynthesis, delaying the second step according to the soft tissue appearance, led to limitation of the ischemic skin lession.

Minimally invasive internal fixation or limited open approach locked plate fixation performed after the dissappearance of the local edema, as the second surgical step, allows anatomically correct articular reconstruction without skin complications, with decrease of arthitic late complications.

\section{References}

1. Tornetta, P., 3rd \& Gorup, J. (1996). Axial computed tomography of pilon fractures. Clin Orthop Relat Res. (323), 273-276.

2. Hindman, B.W., Ross, S.D. \& Sowerby, M.R. 
(1986). Fractures of the talus and calcaneus: evaluation by computed tomography. J Comput Tomogr. 10(2), 191-196.

3. Jia, B., Zhang, Y., Li, Z.L., Cao, G.Q. \& Liu, Y.X. (2011). [Classification of pilon fractures by computed tomography and its guide to clinical treatment]. Zhongguo Gu Shang. 24(6), 470-473.

4. Chen, L., O'Shea, K. \& Early, J.S. (2007). The use of medial and lateral surgical approaches for the treatment of tibial plafond fractures. J Orthop Trauma. 21(3), 207-211. doi: 10.1097/01. bot. $0000246410.25423 .3 \mathrm{e}$

5. Bastian, L., Blauth, M., Thermann, H. \& Tscherne, H. (1995). [Various therapy concepts in severe fractures of the tibial pilon (type $\mathrm{C}$ injuries). A comparative study]. Unfallchirurg. 98(11), 551-558.

6. Jacob, N., Amin, A., Giotakis, N., Narayan, B., Nayagam, S. \& Trompeter, A.J. (2015). Management of high-energy tibial pilon fractures. Strategies Trauma Limb Reconstr. 10(3), 137147. doi: 10.1007/s11751-015-0231-5

7. Assal, M., Ray, A. \& Stern, R. (2007). The extensile approach for the operative treatment of high-energy pilon fractures: surgical technique and soft-tissue healing. J Orthop Trauma. 21(3), 198-206. doi: 10.1097/BOT.0b013e3180316780
8. Bucholz, R.W., Court-Brown, C.M., Heckman, J.D. \& Tornetta, P. (2010). Pilon Fractures in Rockwood and Green's Fractures in Adults: Wolters Kluwer Health/Lippincott Williams \& Wilkins.

9. Gulabi, D., Toprak, O., Sen, C., Avci, C.C., Bilen, E. \& Saglam, F. (2012). The mid-term results of treatment for tibial pilon fractures. Ulus Travma Acil Cerrahi Derg. 18(5), 429-435. doi: 10.5505/ tjtes.2012.86094

10. Marsh, J.L., Lavini, F. (2001). Distal tibial and pilon fractures. Operative technique. Orthofix Operative Technique Manual n.7. In: www. orthofix.com

11. Marin, L.E., Wukich, D.K. \& Zgonis, T. (2006). The surgical management of high- and lowenergy tibial plafond fractures: A combination of internal and external fixation devices. Clin Podiatr Med Surg. 23(2), 423-444, vii.

12. Queitsch, C., Kienast, B., Fuchs, S. \& Seide, K. (2006). [Fracture of the distal lower limb: twostage surgical treatment with external fixator and locked-screw plate]. Zentralbl Chir. 131(3), 194199. doi: 10.1055/s-2006-921557

13. Patterson, M.J. \& Cole, J.D. (1999). Two-staged delayed open reduction and internal fixation of severe pilon fractures. J Orthop Trauma. 13(2), 85-91. 